\title{
An Immunohistochemical Study of Ovarian Follicle Histogenesis in the Early Post-hatch Japanese Quail (Coturnix coturnix japonica)
}

\author{
M.-C. MADEKUROZWA \\ Department of Anatomy and Physiology, University of Pretoria, Private bag X04, \\ Onderstepoort 0110, South Africa. Tel: +27 12529 8417. Fax: +27 125298320. \\ e-mail: mary.madekurozwa@up.ac.za
}

With 6 figures

Short version of title: Early post-hatch ovarian development

\section{Summary}

The early post-hatch development of immunoreactivity to vimentin, desmin, smooth muscle actin (SMA) and laminin, in relation to follicle histogenesis, was described in the present study. Ovigerous cords in day old quails contained pre-granulosa and oocytes. Pre-granulosa cells at the corticomedullary junction were vimentin immunopositive. A laminin immunopositive basement membrane and desmin immunopositive mesenchymal cells lined the ovigerous cords. Ovigerous cords in 3 day old quails contained developing primordial follicles, the vimentin immunopositive pre-granulosa cells of which were partially encircled by a basement membrane and desmin immunopositive mesenchymal cells. In 5 to 7 day old quails, ovigerous cords formed an outer cortical region, while primordial follicles formed the inner cortical region. Early pre-vitellogenic follicles were present in 9 to 13 day old quails. Underlying the granulosa cells of these follicles was a laminin 
immunopositive basement membrane and a layer of desmin immunopositive thecal cells. Early and late pre-vitellogenic follicles dominated the ovary in 15 to 17 day old quails. The thecal layer in these follicles was desmin immunopositive, but SMA immunonegative.

The results of the study have shown that the process of primordial follicle development in the Japanese quail is similar to that reported in mammals. The study suggests that in the quail pre-granulosa cells originate predominantly from the medulla. The study has shown that, in the Japanese quail, thecal cells are derived from desmin immunopositive mesenchymal cells lining the ovigerous cords.

Key words: quail, ovary, folliculogenesis, immunohistochemistry, cytoskeletal proteins, laminin.

\section{Introduction}

Several studies have demonstrated the presence of the cytoskeletal proteins, vimentin, desmin and smooth muscle actin (SMA) in the ovaries of birds and mammals (Van Nassauw et al., 1992a,b; Marettova and Maretta, 2002; Madekurozwa and Kimaro, 2006; Madekurozwa, 2007). Studies have shown that the sequences of the intermediate filaments, vimentin and desmin, as well as the microfilament actin have been conserved during evolution (Nelson and Traub, 1982; Kabsch and Vandekerckhove, 1992; Galkin et al., 2010). It is known that vimentin, desmin and SMA are involved in cellular differentiation and support (Amsterdam and Aharoni, 1994; Galou et al., 1997).

Vimentin has been localized in the granulosa cells of healthy and atretic follicles, while desmin and SMA have been demonstrated in cortical 
and thecal smooth muscle cells (Van den Hurk et al., 1995; Khan-Dawood et al., 1996; Madekurozwa and Kimaro, 2006). In addition to providing a structural framework for the ovary, thecal and cortical smooth muscle cells are involved in the ovulatory process (Martin and Talbot, 1981; Van Nassauw et al., 1992b; 1993).

In addition to desmin and SMA, smooth muscle cells are characterized by the presence of an enclosing basement membrane, which is immunopositive for the glycoprotein laminin (Abd-Elmaksoud, 2009). It is known that the basement membrane plays an important role in follicular formation, maturation and atresia (Bagavandoss et al., 1983; Mazaud et al., 2005). The sequence of laminin has been conserved through evolution (Mota et al., 1988; Hynes and Zhao, 2000). The evolutionary conservation of sequences in laminin has made it possible to use rabbit anti-laminin antibodies to localize laminin in the quail ovary (Rodler and Sinowatz, 2011).

Despite the importance of cytoskeletal proteins and laminin in cellular differentiation, no information is available on post-hatch developmental changes of these constituents in birds. In addition, studies on ovarian development in birds have focussed mainly on embryonic stages, with limited information being available on the post-hatch period (Yoshimura and Nishikori, 2004). In contrast, several studies have been conducted on the developing ovary in the mammalian neonate (Hirshfield and DeSanti, 1995; Ullmann, 1996; Mazaud et al., 2005; Guittot et al., 2006; Kerr et al., 2006).

The present study describes follicle histogenesis, in the post-hatch Japanese quail, in relation to changes in the distribution of vimentin, desmin, SMA and laminin immunoreactivity. 


\section{Materials and Methods}

A total of 45 newly hatched Japanese quail chicks were maintained in a temperature-controlled room, with a light regime of $14 \mathrm{~h}$ light: $10 \mathrm{~h}$ dark. Feed and water were provided ad libitum. Five birds were administered with an overdose of sodium pentobarbital anaesthetic (Sagatal, May and Baker, South Africa) at $1,3,5,7,9,11,13,15$ and 17 days post-hatch. All the procedures used in this study were approved by the Animal Use and Care Committee of the University of Pretoria.

The thoraco-abdominal cavity was cut open, and the ovary was removed. Ovarian tissue was immersion-fixed in $4 \%$ phosphate buffered formaldehyde for $48 \mathrm{~h}$. After fixation, tissues were processed routinely for histology and embedded in paraffin wax. The immunostaining technique was performed on $5 \mu \mathrm{m}$ thick sections using a Universal LSAB-plus kit, Peroxidase (DakoCytomation, Glostrup, Denmark).

Sections were deparaffinized and endogenous peroxidase activity was blocked, using a $3 \%(\mathrm{v} / \mathrm{v})$ hydrogen peroxide solution in water for $5 \mathrm{~min}$. The slides were then rinsed in a $0.01 \mathrm{M}$ phosphate buffered saline solution (PBS, $\mathrm{pH}$ 7.4) for $5 \mathrm{~min}$. Thereafter, the sections for vimentin, desmin and SMA immunohistochemistry were microwaved at $750 \mathrm{~W}$ for three cycles of $7 \mathrm{~min}$ each. After being allowed to cool for $20 \mathrm{~min}$ the sections were rinsed with PBS. Antigen retrieval on sections for laminin immunohistochemistry was performed by incubating the sections with Proteinase $\mathrm{K}$ (Dakocytomation, Glostrup, Denmark) in a $0.05 \mathrm{~mol} / \mathrm{L}$ Tris- $\mathrm{HCl}(\mathrm{pH} 7.6)$ solution for $6 \mathrm{~min}$.

The sections were incubated for $30 \mathrm{~min}$ at room temperature with monoclonal antibodies against desmin, vimentin and smooth muscle actin at 
dilutions of 1:50, 1:100 and 1:50 respectively. In addition, a polyclonal laminin antibody at a dilution of 1:100 was used. The primary antisera were purchased from Dakocytomation, Glostrup, Denmark. The mouse anti-human desmin, as well as the mouse anti-human smooth muscle actin antibodies used in this study have previously been used to immunolocalize actin in smooth muscle cells of the quail testis and excurrent ducts (Aire and Ozegbe, 2007, 2008). The mouse anti-bovine vimentin antibody used in the present study has been used to immunolocalize vimentin in fibroblasts of the quail testis and excurrent ducts (Aire and Ozegbe, 2007, 2008). In addition, the antibody has been used to immunolocalize vimentin in the surface epithelium of the quail ovary (Rodler and Sinowatz, 2011).

After the incubation with primary antibodies the slides were rinsed with PBS and then incubated for 15 min with a biotinylated secondary antibody (LSAB-plus kit). Thereafter, the slides were rinsed in PBS and subsequently incubated for 15 min with the streptavidin peroxidase component of the LSABplus staining kit. Slides were then rinsed in PBS and bound antibody was visualized after the addition of a 3,3'-diaminobenzidine tetrachloride solution (LSAB-plus kit). The sections were counter-stained with Mayer's haematoxylin.

In the negative controls the monoclonal desmin, vimentin and SMA antibodies were replaced with mouse IgG1 (Dakocytomation, Glostrup, Denmark), while the polyclonal laminin antibody was substituted with rabbit immunoglobulin fraction (Dakocytomation, Glostrup, Denmark). The negative control reagents were diluted to the same concentration as the primary antibodies. Smooth muscle was used as a positive control for desmin, SMA 
and laminin, while tonsillar tissue was used as a positive control for vimentin. Variations in the immunostaining of sections used in this study were minor. No background staining was detected in the negative control sections, while positive immunostaining for vimentin, desmin, SMA and laminin was observed in the control sections.

\section{Results}

\section{1 day old quails}

The cortex was composed of ovigerous cords, which extended from the surface epithelium to the medulla (Fig. 1). The ovigerous cords were composed of oocytes and pre-granulosa cells. Pre-granulosa cells at the cortico-medullary junction and occasional surface epithelium cells displayed vimentin immunostaining (Fig. 2a). The surface epithelium and ovigerous cords were lined by a continuous laminin immunopositive basement membrane, which resulted in contact between surface epithelial cells and the ovigerous cords (Fig. 2b). Underlying the basement membrane of the ovigerous cords were desmin immunopositive mesenchymal cells (Fig. 1 \& 2c). The mesenchymal cells were SMA immunonegative. The tunica media of blood vessels between the ovigerous cords and within the medulla displayed desmin, laminin and SMA immunostaining (Fig. 2d).

\section{3 day old quails}

The ovigerous cords contained oocytes and pre-granulosa cells, except at the cortico-medullary junction where developing primordial follicles (approximately 20 to $30 \mu \mathrm{m}$ ) were observed. The vimentin immunopositive pre-granulosa 
cells of developing primordial follicles were partially encircled by an invaginating laminin immunopositive basement membrane (Fig. 3b). Peripheral to the basement membrane were desmin immunopositive mesenchymal cells (differentiating thecal cells), which extended into the ovigerous cords from the interstitium (Fig. 3a).

\section{5 to 7 day old quails}

A laminin immunopositive basement membrane and desmin immunopositive mesenchymal cells subdivided the cortex into two regions. The outer cortical region contained ovigerous cords, while the inner region contained primordial follicles. The vimentin immunopositive granulosa cells of the primordial follicles (Fig. 4a) were enclosed by a continuous laminin immunopositive basement membrane, which was surrounded by a desmin immunopositive thecal layer (Fig. 4b). The thecal layer was immunonegative for SMA, but displayed weak laminin immunostaining.

\section{9 to 13 day old quails}

Due to the absence of ovigerous cords, the surface epithelium was lined by a continuous laminin immunopositive basement membrane. The cortex was composed of primordial follicles and early pre-vitellogenic follicles, which were approximately 100 to $150 \mu \mathrm{m}$ in diameter (Fig. 5a). The oocyte in early previtellogenic follicles was surrounded by a simple cuboidal to columnar granulosa layer, which was vimentin immunopositive (Fig. 5b). Underlying the granulosa layer was a laminin immunopositive basement membrane (Fig. 5a), and a single layer of desmin immunopositive thecal cells (Fig. 5c). The thecal 
layer was smooth muscle actin immunonegative (Fig. 5d), but demonstrated weak laminin immunostaining.

\section{5 to 17 day old quails}

Early and late pre-vitellogenic follicles dominated the ovary in 15 to 17 day old quails. In the late pre-vitellogenic follicles (approximately 300 to $750 \mu \mathrm{m}$ in diameter) the oocyte was surrounded by a vimentin immunopositive pseudostratified columnar granulosa layer (Fig. 6a). The enclosing thecal layer contained three to four layers of cells, which were immunopositive for desmin (Fig. 6b), but immunonegative for SMA (Fig. 6c). The thecal layer in pre-vitellogenic follicles had not differentiated into interna and externa components.

Groups of interstitial gland cells, circumscribed by desmin immunopositive cells (Fig. 6b) and a laminin immunopositive basement membrane, were observed along the lateral and basal regions of late previtellogenic follicles. The cells encircling the interstitial glands were SMA immunonegative (Fig. 6c).

Strong laminin immunostaining was localized in the basement membranes underlying the surface epithelium and granulosa cells (Fig. 6d). The thecal layer of the pre-vitellogenic follicles exhibited weak laminin immunostaining. 


\section{DISCUSSION}

The study describes the development of immunoreactivity to vimentin, laminin, desmin and SMA, in relation to follicle histogenesis, in the post-hatch quail ovary. The morphology of primordial, early and late pre-vitellogenic follicles, observed in the present study, was similar to that described in the adult Japanese quail (Van Nassauw et al., 1992a,b), ostrich (Madekurozwa and Kimaro, 2006) and emu (Madekurozwa, 2007).

The process of primordial follicle development, in the post-hatch Japanese quail, is similar to that of the mouse (Frojdman et al., 1995), rat (Hirshfield and DeSanti, 1995; Guittot et al., 2006), brushtail possum (Ullmann, 1996) and sheep (Juengel et al., 2002; Sawyer et al., 2002).

In the present study, the formation of primordial follicles was evident from day one post-hatch, with pre-granulosa cells at the cortico-medullary interface displaying vimentin immunostaining. The localization of vimentin immunopositive pre-granulosa cells at the cortico-medullary interface suggests that in the Japanese quail pre-granulosa cells originate predominantly from the medulla. This is supported by research on ovarian development in the brushtail possum (Ullmann, 1996), which has shown that pre-granulosa cells located in the cortico-medullary region are derived from disintegrating cellular cords located in the medulla (Ullmann, 1996). Further research by Juengel et al. (2002) and Sawyer et al. (2002) has shown that upon establishment of a basement membrane around the ovigerous cords and below the surface epithelium, pre-granulosa cells of developing primordial follicles can only be recruited from the surface epithelium. In the present study few cells in the surface epithelium displayed vimentin immunostaining. This 
finding suggests that the surface epithelium contributes a limited number of pre-granulosa cells in the post-hatch quail ovary.

In the Japanese quail primordial follicles were isolated from the ovigerous cords once the basement membrane had completely surrounded the pre-granulosa cells of developing follicles. Ultrastructural and immunofluorescence studies on follicle histogenesis in the rat (Mazaud et al. 2005) have shown that the process of primordial follicle detachment involves the formation of clefts within the ovigerous cords, into which basement membrane components are deposited. These findings correlate well with the results of the present study, in which the extension of the developing basement membrane between cells of the ovigerous cords was clearly demonstrated by laminin immunostaining.

Studies on the formation of the thecal layer in mammals have shown that thecal cells are derived from mesenchymal cells, which migrate into the ovigerous cords from the adjacent interstitium (Hirshfield, 1991; Mazaud et al. 2005). Although several studies have described the development of oocytes and granulosa cells in birds, little mention is made of the formation of the thecal cell layer. The current study has shown that desmin immunopositive mesenchymal cells from the cortico-medullary junction and areas between the ovigerous cords are incorporated into developing primordial follicles to form the thecal layer.

Although both desmin and SMA are markers for smooth muscle cells, the thecal cells in primordial and pre-vitellogenic follicles of the Japanese quail were immunopositive for desmin, but consistently immunonegative for SMA. Studies on the Japanese quail (Van Nassauw et al., 1992a,b), ostrich 
(Madekurozwa and Kimaro, 2006) and emu (Madekurozwa, 2007) have shown that the distribution of desmin and SMA in the avian ovary is species dependent. Furthermore, these studies have shown that the distribution of desmin and SMA changes with follicular maturation. In the ostrich, thecal cells of primordial follicles were desmin and SMA immunonegative, while the thecal cells of pre-vitellogenic follicles were immunopositive for both desmin and SMA (Madekurozwa and Kimaro, 2006). In contrast, in the emu desmin immunostaining was localized in pericytes in the theca interna, while SMA immunostaining was demonstrated in the theca externa of vitellogenic follicles (Madekurozwa, 2007).

In the present study weak laminin immunostaining was observed in the thecal cells of primordial and pre-vitellogenic follicles. Research conducted by Bagavandoss et al. (1983), on the developing ovary in the rat, has shown that the thecal layer synthesizes the laminin component of the basement membranes associated with ovarian follicles. Using immunohistochemical and immunoelectron microscopic techniques, Leardkamolkarn and Abrahamson (1992) localized laminin within both thecal and granulosa cells, indicating that these cells are involved in the synthesis of the basement membrane in ovarian follicles.

In conclusion, the results of the present study have shown that the processes of primordial follicle development from ovigerous cords are similar to that observed in mammals. Based on the concentration of vimentin immunopositive pre-granulosa cells at the cortico-medullary interface, it would appear that in the Japanese quail granulosa cells originate predominantly from the medulla. Furthermore, the results indicate that thecal cells are 
derived from desmin immunopositive mesenchymal cells located at the cortico-medullary junction and in the areas between adjacent ovigerous cords.

\section{Acknowledgements}

The author thanks staff in the Department of Pathology, University of Pretoria, for their assistance. The National Research Foundation funded this study.

\section{References}

Abd-Elmaksoud, A, 2009: Comparative expression of laminin and smooth muscle actin in the testis and epididymis of poultry and rabbit. J. Mol. Histol. 40, 407-416.

Aire, T.A., and P.C. Ozegbe, 2007: The testicular capsule and peritubular tissue of birds: morphometry, histology, ultrastructure and immunohistochemistry. J. Anat. 210, 731-740.

Aire, T.A., and P.C. Ozegbe, 2008: Immunohistochemistry of the cytoskeleton in the excurrent ducts of the testis in birds of the Galloanserae monophyly. Cell Tiss. Res. 333, 311-321.

Amsterdam, A., and D. Aharoni, 1994: Plasticity of cell organization during differentiation of normal and oncogene transformed granulosa cells. Microsc. Res. Tech. 27, 108-124.

Bagavandoss, P., A.R. Midgley, and M. Wicha, 1983: Developmental changes in the ovarian follicular basement membrane detected by immunofluorescence and electron microscopy. J. Histochem. Cytochem. 31, 633-640.

Frojdman, K., P. Ekblom, L. Sorokin, A. Yagi, and L.J. Pelliniemi, 1995: 
Differential distribution of laminin chains in the development and sex differentiation of mouse internal genitalia. Int. J. Dev. Biol. 39, 335-344. Galkin, V.E., A. Orlova, G. Schroder, and E.H. Egelman, 2010: Structural polymorphism in F actin. Nat. Struct. Mol. Biol. 17, 1318-1323.

Galou, M., J. Gao, J. Humbert, M. Mericskay, Z. Li, D. Paulin, and P. Vicart, 1997: The importance of intermediate filaments in the adaptation of tissues to mechanical stress: evidence from gene knockout studies. Biol. Cell. 89, 85-97.

Guittot, S.M., C.J. Guigon, N. Coudouel, and S. Magre, 2006: Consequences of fetal irradiation on follicle histogenesis and early follicle development in rat ovaries. Biol. Reprod. 75, 749-759.

Hirshfield, A.N., 1991: Theca cells may be present at the outset of follicular growth. Biol. Reprod. 44, 1157-1162.

Hirshfield, A.N., and A.M. DeSanti, 1995: Patterns of ovarian cell proliferation in rats during the embryonic period and the first three weeks postpartum. Biol. Reprod. 53, 1208-1221.

Hynes, R.O., and Q. Zhao, 2000: The evolution of cell adhesion. J. Cell. Biol. 150, F89-F95.

Juengel, J.L., H.R. Sawyer, P.R. Smith, L.D. Quirke, D.A. Heath, S. Lun, S.J. Wakefield, and K.P. McNatty, 2002: Origins of follicular cells and ontogeny of steroidogenesis in ovine fetal ovaries. Mol. Cell. Endocr. 191, 1-10.

Kabsch, W., and J. Vandekerckhove, 1992: Structure and function of actin. Annu. Rev. Biophys. Biolmol. Struct. 21, 49-76.

Kerr, J.B., R. Duckett, M. Myers, K.L. Britt, T. Mladenovska, and J.K. Findlay, 
2006: Quantification of healthy follicles in the neonatal and adult mouse ovary: evidence for maintenance of primordial follicle supply. 132 , 95109.

Khan-Dawood, F.S., M.Y. Dawood, and S. Tabibzadeh, 1996:

Immunohistochemical analysis of the microanatomy of primate ovary. Biol. Reprod. 54, 734-742.

Leardkamolkarn, V., and D.R. Abrahamson, 1992: Immunoelectron microscopic localization of laminin in rat ovarian follicles. Anat. Rec. 233, 41-52.

Madekurozwa, M.-C., 2007: An immunohistochemical study of the distribution of intermediate filaments in the ovary of the emu (Dromaius novaehollandiae). Anat. Histol. Embryol. 36, 336-342.

Madekurozwa, M.-C., and W.H. Kimaro, 2006: A morphological and immunohistochemical study of healthy and atretic follicles in the ovary of the sexually immature ostrich (Struthio camelus). Anat. Histol. Embryol. 35, 253-258.

Marettova, E., and M. Maretta, 2002: Demonstration of intermediate filaments in sheep ovary. Acta Histochem. 104, 431-434.

Martin, G.G., and P. Talbot, 1981: The role of follicular smooth muscle cells in hamster ovulation. J. Exp. Zool. 216, 469-482.

Mazaud, S., R. Guyot, C.J. Guigon, N. Coudouel, B. Le MagueresseBattistoni, and S. Magre, 2005: Basal membrane remodeling during follicle histogenesis in the rat ovary: contribution of proteinases of the MMP and PA families. Dev. Biol. 277, 403-416.

Mota, G.F.A., C.R.W. Carneiro, L. Gomes, and J.D. Lopes, 1988: Monoclonal 
antibodies to Staphylococcus aureus laminin-binding proteins cross react with mammalian cells. Infection and Immunity. 56, 1580-1584.

Nelson, J.W., and P. Traub, 1982: Intermediate $(10 \mathrm{~nm})$ filament proteins and the Ca 2+ - activated proteinase specific for vimentin and desmin in the cells from fish to man: an example of evolutionary conservation. J. Cell. Sci. 57, 25-49.

Rodler, D., and F. Sinowatz, 2011: Immunohistochemical and ultrastructural characterization of the ovarian surface epithelium of Japanese quail (Coturnix japonica). Ani. Sci. J. 82, 307-313.

Sawyer, H.R., P. Smith, D.A. Heath, J.L. Juengel, St. J. Wakefield, and K.P. McNatty, 2002: Formation of ovarian follicles during fetal development in sheep. Biol. Reprod. 66, 1134-1150.

Ullmann, S.L., 1996: Development of the ovary in the brushtail possum Trichosurus vulpecula (Marsupialia). J. Anat. 189, 651-665.

Van den Hurk, R., G. Dijkstra, F.N. Van Mil, S.C.J. Hulshof, and S.G.A.M. Van den Ingh, 1995: Distribution of the intermediate filament proteins vimentin, keratin and desmin in the bovine ovary. Mol. Reprod. Dev. 41, 459-467.

Van Nassauw, L., F. Harrisson, and M. Callebaut, 1992a: Immunolocalization of smooth muscle-like cells in the quail ovary. Eur. J. Morph. 30, 275288.

Van Nassauw, L., M. Callebaut, F. Harrisson, and D.W. Scheuermann, 1992b: Smooth muscle cells in the walls of ovarian follicles in the Japanese quail. Cell Tiss. Res. 269, 49-56.

Van Nassauw, L., S.U. Sys, F. Harrisson, and M. Callebaut, 1993: In vitro 
study of the contractility of the wall of the preovulatory follicle in the Japanese quail. Biol. Reprod. 49, 359-364.

Yoshimura, Y., and M. Nishikori, 2004: Identification of apoptotic oocytes

in the developing ovary of embryonic and post-hatched chicks in Japanese quail (Coturnix japonica). J. Poult. Sci. 41, 64-68. 


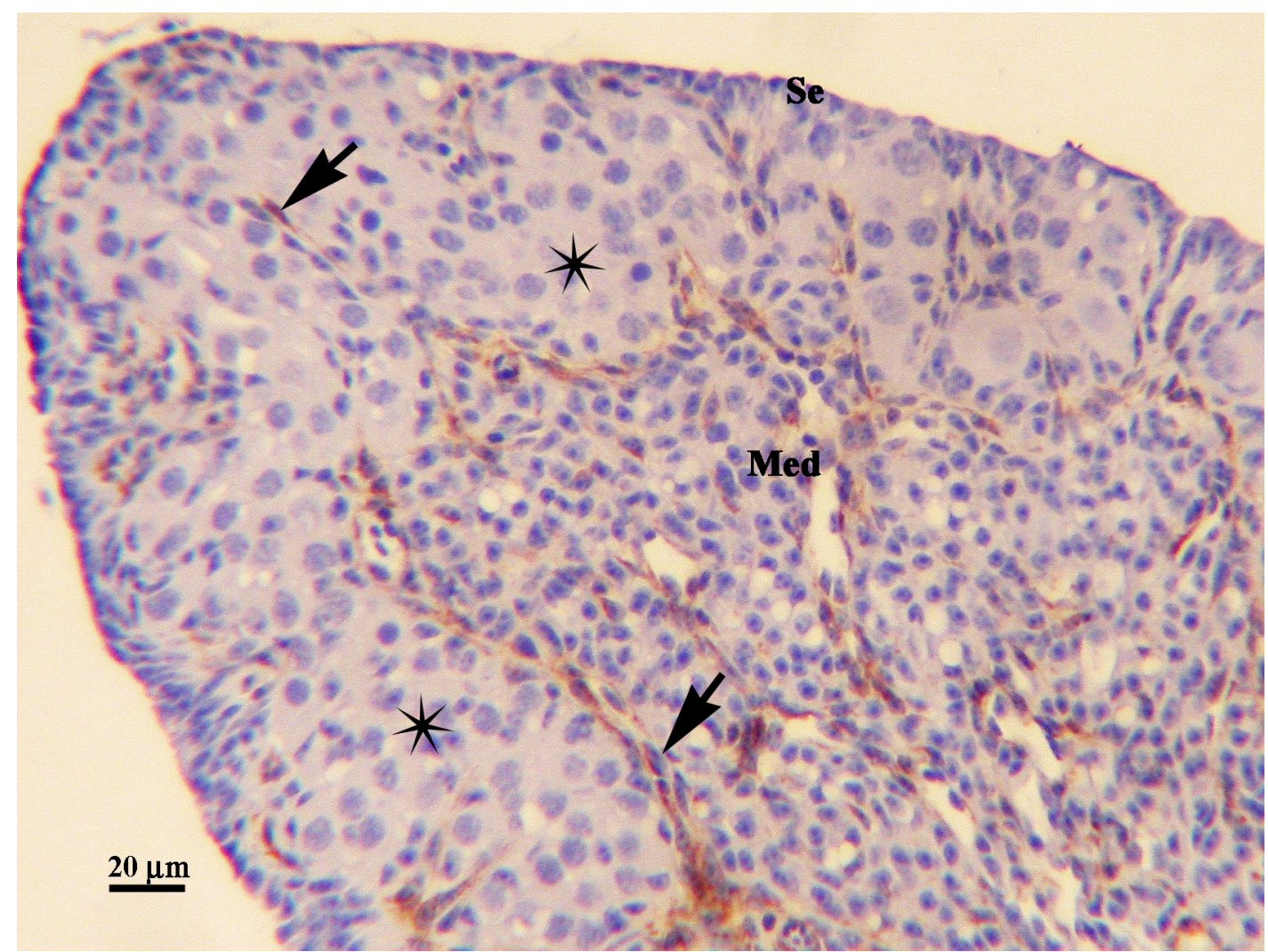

Figure 1. 1 day post-hatch. Survey photomicrograph of the ovary. Se: surface epithelium. Asterisks: ovigerous cords. Arrows: desmin immunopositive cells. Med: medulla. 

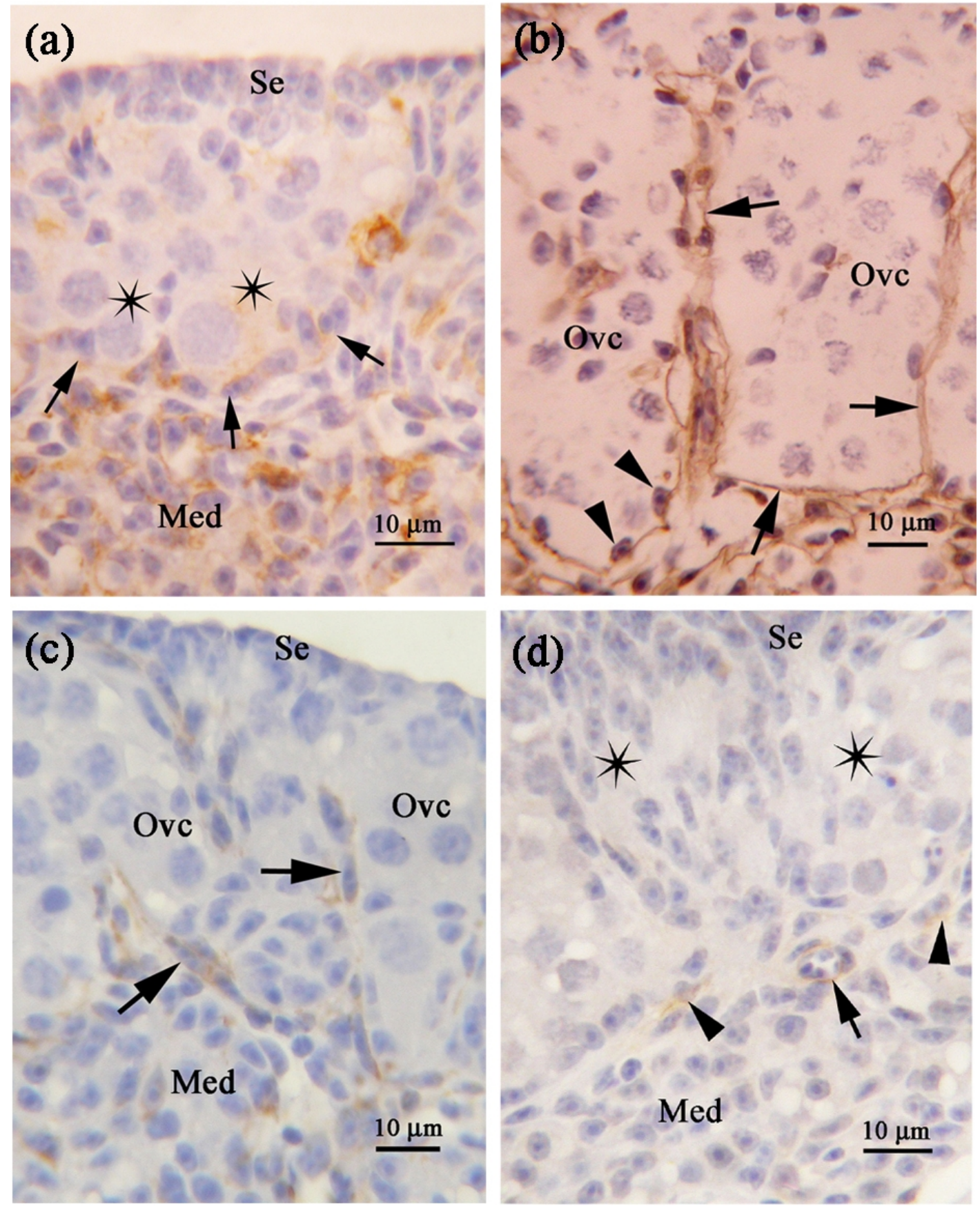

Figure 2. 1 day post-hatch. (a) Vimentin immunopositive pre-granulosa cells (arrows) line oocytes (asterisks) at the cortico-medullary junction. Se: surface epithelium. Med: medulla. (b) A laminin immunopositive basement membrane (arrows) lines ovigerous cords (Ovc). Arrowheads: pre-granulosa cells.(c) Desmin immunopositive mesenchymal cells (arrows) extend between ovigerous cords (Ovc). Se: surface epithelium. Med: medulla. (d) SMA immunostaining (arrow) in the tunica media of a blood vessel adjacent to ovigerous cords (asterisks). Isolated cells (arrowheads) at the cortico-medullary junction display SMA immunostaining. Se: surface epithelium. Med: medulla. 


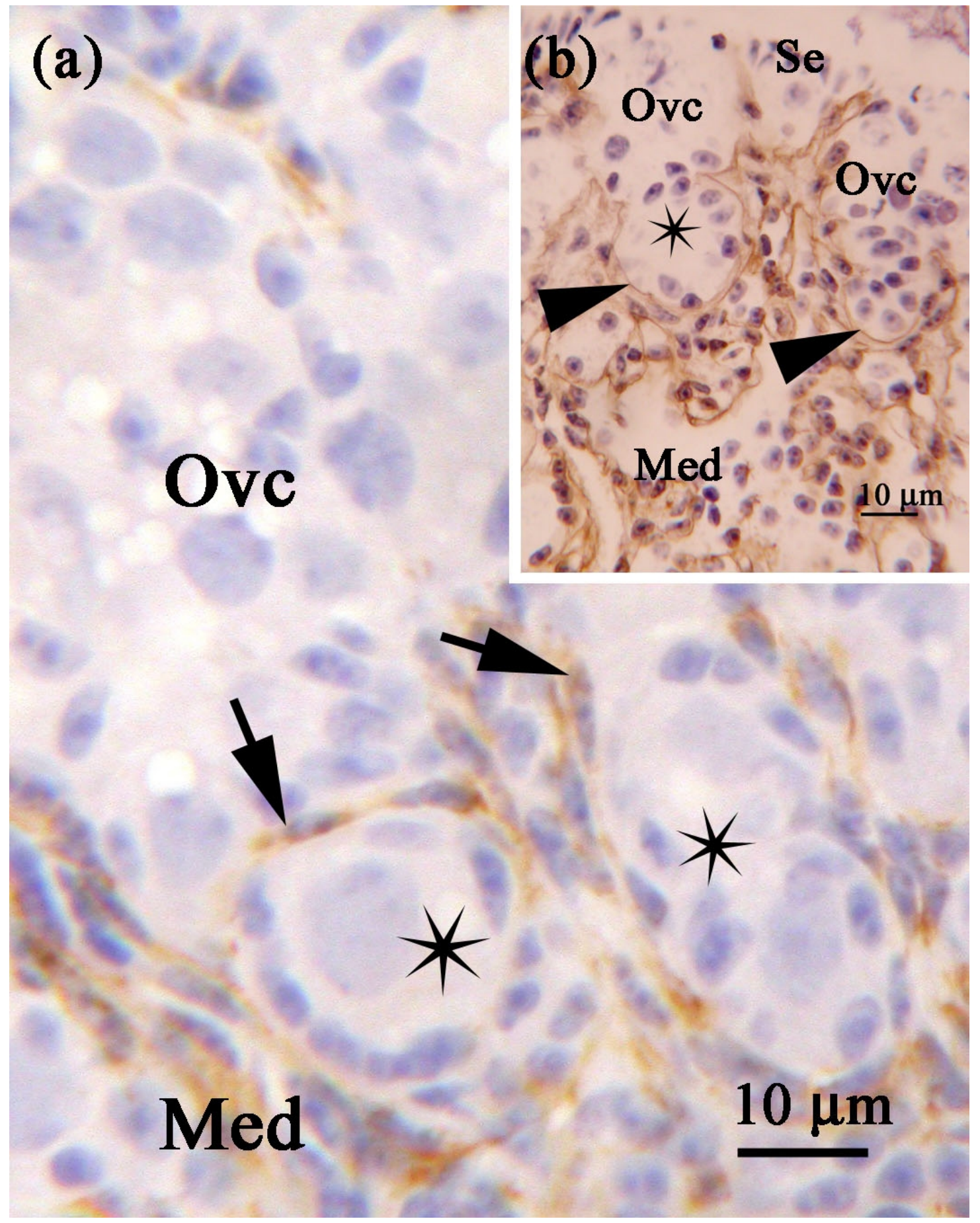

Figure 3. 3 days post-hatch. (a) Developing primordial follicles (asterisks) partially enclosed by desmin immunopositive mesenchymal cells (arrows). Ovc: ovigerous cord. Med: medulla. (b) A laminin immunopositive basement membrane (arrowheads) lines ovigerous cords (Ovc) and a developing primordial follicle (asterisk). Note the absence of a basement membrane below the surface epithelium (Se). Med: medulla. 

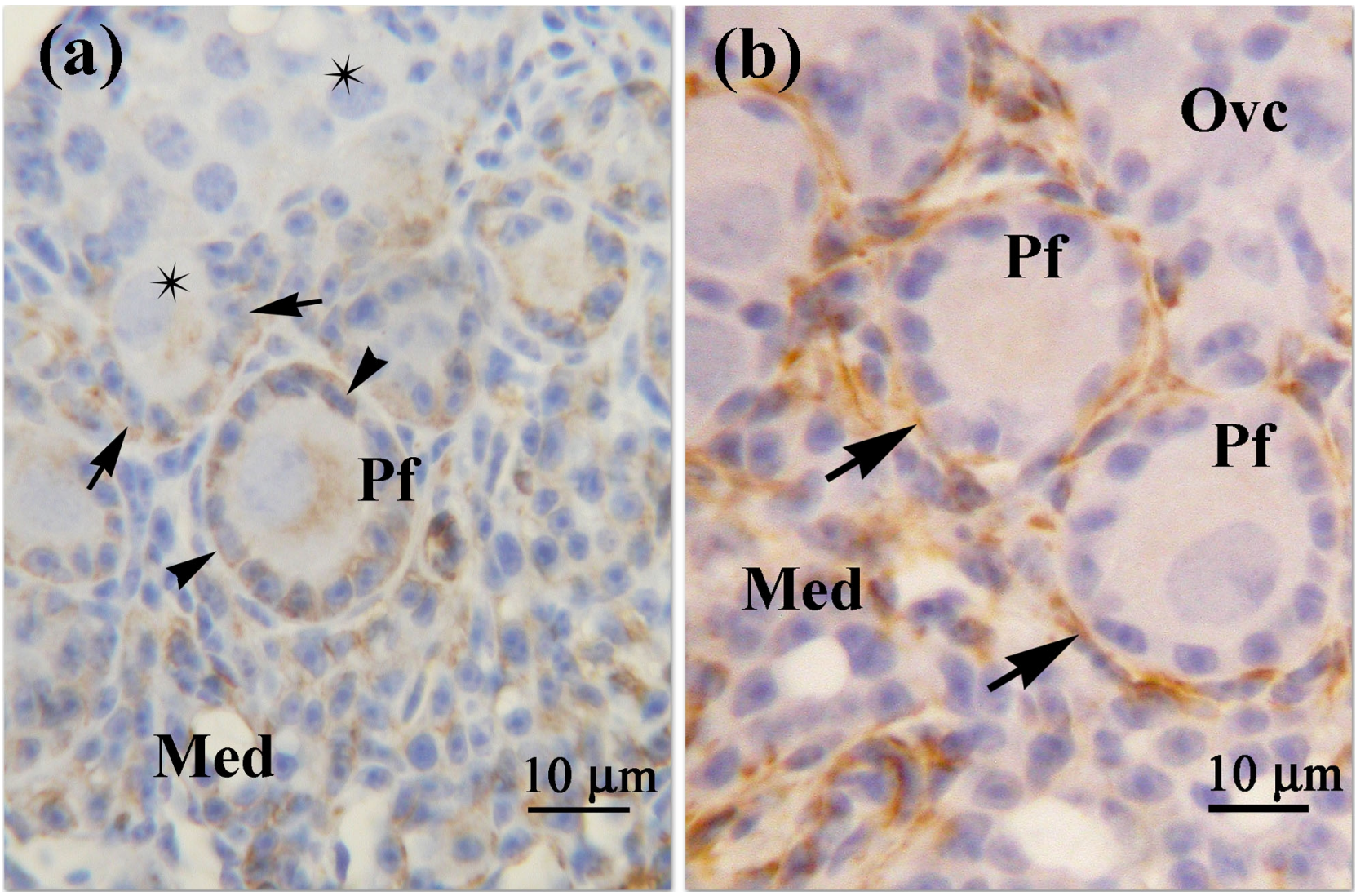

Figure 4. (a) 5 days post-hatch. Vimentin immunopositive pre-granulosa (arrows) and granulosa cells (arrowheads). Asterisks: oocytes. Pf: primordial follicle. Med: medulla. (b) 7 days post-hatch. Primordial follicles (Pf) with desmin immunopositive thecal cells (arrows). Ovc: ovigerous cord. Med: medulla. 

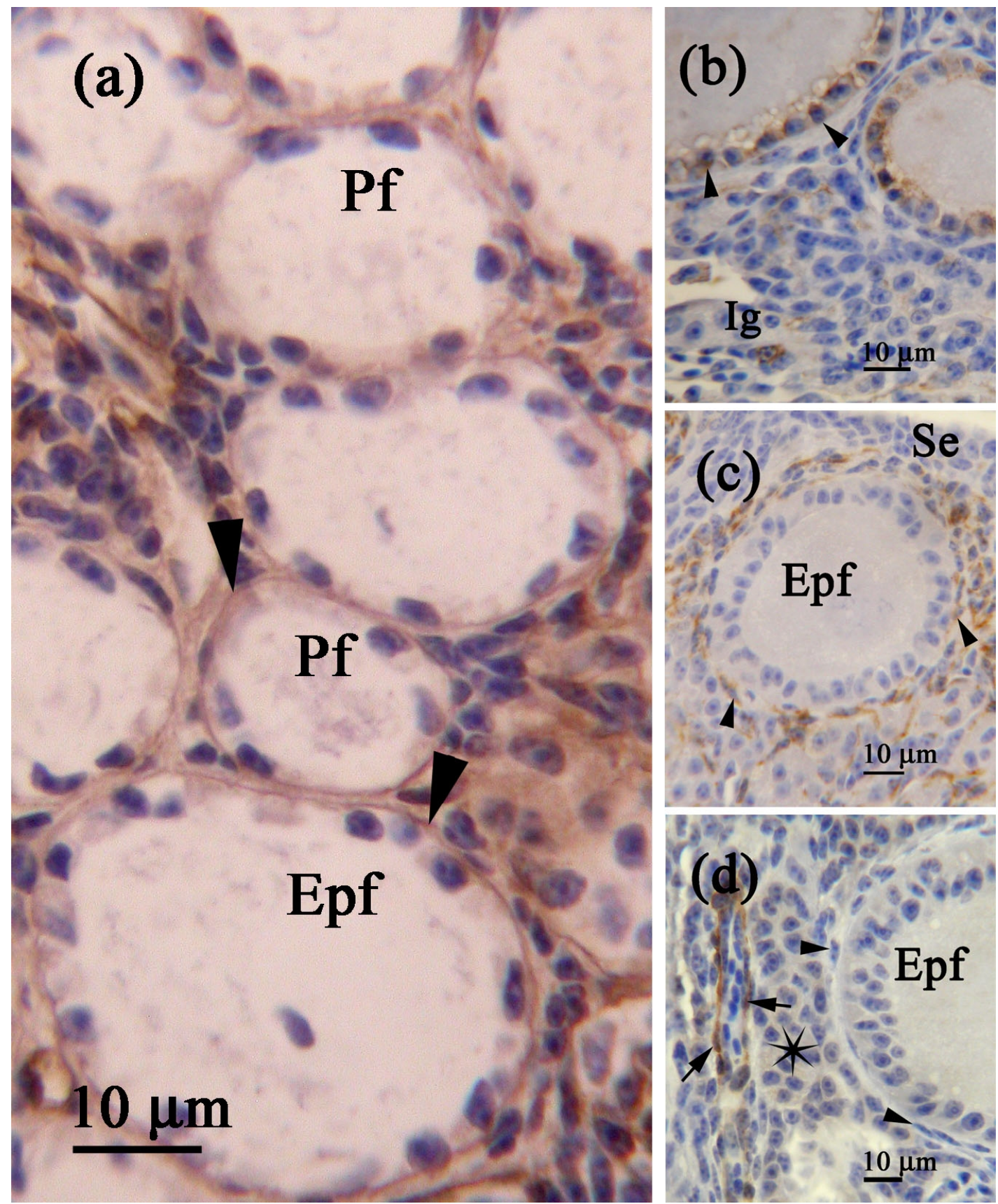

Figure 5. (a) 9 days post-hatch. Primordial (Pf) and early pre-vitellogenic (Epf) follicles. Arrowheads: laminin immunopositive basement membranes. (b) 13 days post-hatch. Vimentin immunostaining in the granulosa cells (arrowheads) of an early pre-vitellogenic follicle. Ig: interstitial gland. (c) 11 days post-hatch. Early pre-vitellogenic follicle (Epf) with a desmin immunopositive thecal layer (arrowheads). Se: surface epithelium. (d) 11 days post-hatch. Early pre-vitellogenic follicle (Epf) with a SMA immunonegative thecal layer (arrowheads). Strong SMA immunostaining is demonstrated in the tunica media (arrows) of an adjacent blood vessel. Asterisk: interstitial gland. 

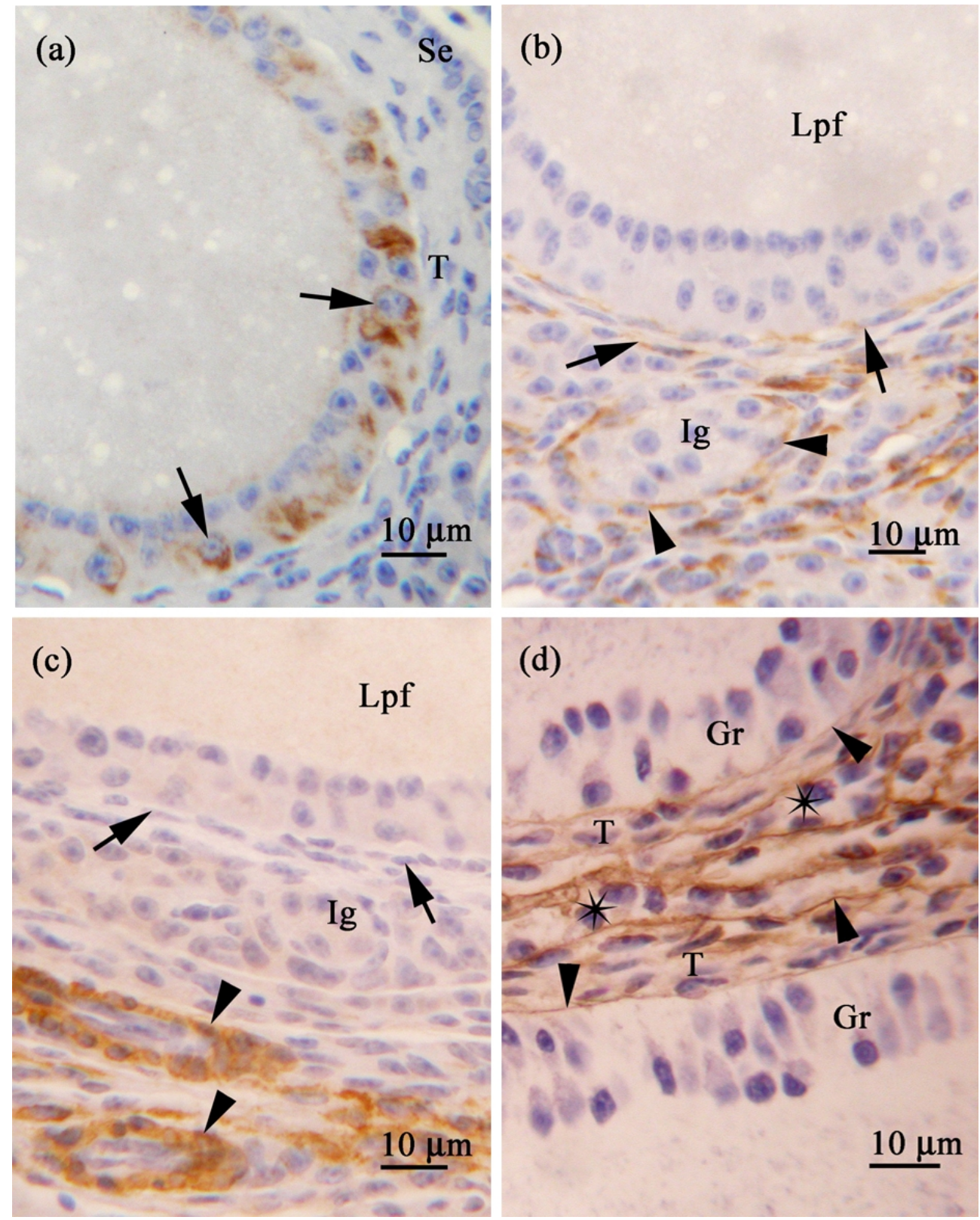

Figure 6. (a) 15 days post-hatch. Vimentin immunopositive granulosa cells (arrows) in a late pre-vitellogenic follicle. T: thecal layer. Se: surface epithelium. (b) 15 days post-hatch. Desmin immunopositive thecal cells (arrows) in a late pre-vitellogenic follicle (Lpf). Desmin immunopositive cells (arrowheads) encircle interstitial glands (lg). (c) 17 days post-hatch. Late pre-vitellogenic follicle (Lpf) with a SMA immunonegative thecal layer (arrows). Strong SMA immunoreactivity is demonstrated in the tunica media (arrowheads) of adjacent blood vessels. Ig: Interstitial gland. (d) 17 days post-hatch. Weak laminin immunostaining in the thecal layers $(T)$ of adjacent late pre-vitellogenic follicles. Strong laminin immunoreactivity is demonstrated in the basement membranes (arrowheads) of granulosa cell layers (Gr) and blood vessels (asterisks). 